\title{
Preface
}

Solitary wasps have been a favorite of naturalists and ethologists for well over a century. As pet subjects of Jean Henri Fabre, wasps provided a generous portion of the material for his Souvenirs Entomologique, first published in I879 and later translated into English (Fabre I9I5, I9I9, I92I). His chapter headings sometimes read like titles of Sherlock Holmes stories: "The Method of the Calicurgi," "The Problem of the Scoliae," and "A Dangerous Diet," for example (Fabre I92I). As was his forensic counterpart, Fabre was a superb detective who used careful observation and deduction in his inquiries. Fabre also asked questions of his subjects that anticipated the interests of later ethologists, addressing topics such as innate behavioral sequences, homing, and sex allocation. His narratives may not be cutting-edge science from our current perspective, but they are certainly informative and entertaining (though often amusingly quaint).

Fabre was just the first of a string of writers fascinated with the lives of solitary wasps-writers such as George and Elizabeth Peckham (I898), Phil and Nellie Rau (I9 I 8), Edward Reinhard (I929), John Crompton (I955), Niko Tinbergen (I958), Howard Evans (I963), and John Alcock (I988). Along the way, these and many other observers have contributed to a vast scientific literature on solitary wasps. I like to remind students that, although the Nobel Prizewinning ethologist Niko Tinbergen is most famous for his research on herring gulls and sticklebacks, his doctoral research concerned the behavior of the solitary wasp Philanthus triangulum. In doing that research, he provided one of the early successes of ethology. Tinbergen's work is an important link between Fabre's work and modern wasp biology.

Solitary wasps still offer behavioral ecologists and evolutionary biologists model organisms for understanding the evolution of forag- 
ing behavior, parental strategies, mating systems, thermoregulation, and eusociality. Fabre, by the way, emphatically rejected the notion of Darwinian evolution, so we can take his inspiration only so far (Pasteur 1994). The future certainly holds much in store as entomologists apply increasingly sophisticated conceptual models and research methods to old and new problems of wasp biology. I hope that this book will encourage others to join in the research, although I must caution that wasp watching can be a nearly addictive habit, not without its minor misadventures and discomforts. Wasp researchers may have to dodge cacti and rattlesnakes while chasing a mating pair or endure heat and wind-blown sand while excavating a nest burrow. Wasps, of course, also share with other animals a frustrating penchant for falsifying pet hypotheses. Nevertheless, one should pay little heed to wasp researchers when they complain. Most wasp biologists of my acquaintance enjoy the physical challenges and surprise observations and may even get satisfaction from doing wasp ethology on a shoestring budget (it's good that they can, because most have no choice in the matter). However, significant contributions to our knowledge of the biology of a wasp species can be made using no more than a pencil, notebook, watch, insect net, pen knife, ruler, and several dollars worth of model airplane paint for giving wasps individual identifying marks. One need only find an unexplored species or population, perhaps dream up a few hypotheses, and settle down to patiently observe and record. Fortunately, there is no shortage of wasps to provide subjects for research and entertainment.

In this book, I have tried to strike a balance between the old and new literature on solitary wasps. Much of the new literature has the obvious merits of being in tune with present-day theory and of taking a quantitative approach. The older literature, though less quantitative, is rich in details on comparative ethology and natural history. Papers published before the rise of modern ethology also have a charm missing from contemporary journals, because our generation has been discouraged from reporting anecdotes and even from placing the research in a personal context. Who today would dare start a journal article with "One fine day in early April I noticed a large, steely blue wasp running awkwardly along the ground on tip toes" (Newcomer I930). Certainly, such writing can become tedious if overdone, but current papers written in sterile, passive-voiced technical prose can make us forget that the author actually studied real animals in a real world. 
Briefly, the plan for the book is as follows. In Chapter I, I provide a cursory overview of the classification of the Hymenoptera. Chapters 2-5 present a review of the foraging strategies of solitary aculeates, emphasizing the diversity of hosts and prey used and the ways in which prey are located and subdued; I also discuss the role of wasps in biological control. In Chapter 6, I discuss the nests of female solitary wasps. Chapter 7 is a review of information on the natural enemies of solitary wasps and the counterstrategies used to combat them. In Chapter 8, I provide an overview of mating strategies, including courtship. Chapter 9 contains a discussion of thermoregulation and sleeping. Chapter Io wraps things up with a discussion of the evolution of parental strategies. Throughout the book, I use case studies of individual species to illustrate the details of behavior, while placing much of the comparative information in tables that can be perused to get a sense of the diversity of behaviors of solitary wasps. I have furnished a list of the superfamilies, families, and subfamilies of solitary aculeate Hymenoptera in Appendix I. To avoid having to give a family affiliation each time a genus is mentioned, I have also provided in Appendix II a list with the family affiliations of all genera discussed in the book.

Many thanks go to John Alcock, whose editorial skills and expertise in wasp biology helped polish a rough manuscript. Howard Evans, Bill Wcislo, and Ruth O'Neill reviewed the entire manuscript, and Byron Alexander, Peter Jensen, Rob Longair, Marni Rolston, Catherine Seibert, Bo Turnbow, and several anonymous reviewers commented on various chapters. Special thanks go to Peter Prescott, Nancy Winemiller, and Lynn Coryell of Cornell University Press, to the Interlibrary Loan staff at Montana State University, and to Massimo Olmi.

Originally, this book was planned to be co-authored with Byron Alexander, who would have contributed chapters on classification and nesting. Unfortunately, Byron had not completed his first chapter at the time of his death in I996. The book is better because of his participation, but not as good as it could have been if he had lived to provide his special touch. I also would have liked to show the book to George Eickwort, who died in I994. As the original editor of the Cornell Series in Arthropod Biology, it was George (along with Rob Reavill of Cornell University Press) who invited me to write the book and who provided some of the inspiration for its organization and approach. 



\section{Solitary Wasps}


